\title{
The Effects of Omega-3 Fatty Acid Supplementation on Dexamethasone-Induced Muscle Atrophy
}

\author{
Alan Fappi, Tiago S. Godoy, Jessica R. Maximino, Vanessa R. Rizzato, \\ Juliana de C. Neves, Gerson Chadi, and Edmar Zanoteli \\ Department of Neurology, University of São Paulo, No. 455, Dr. Arnaldo Avenue, 01246-903 São Paulo, SP, Brazil \\ Correspondence should be addressed to Edmar Zanoteli; zanoteli@terra.com.br
}

Received 18 March 2014; Accepted 28 April 2014; Published 25 May 2014

Academic Editor: Emanuele Marzetti

Copyright (C) 2014 Alan Fappi et al. This is an open access article distributed under the Creative Commons Attribution License, which permits unrestricted use, distribution, and reproduction in any medium, provided the original work is properly cited.

\begin{abstract}
Corticosteroids cause muscle atrophy by acting on proteasomal and lysosomal systems and by affecting pathways related to muscular trophysm, such as the IGF-1/PI-3k/Akt/mTOR. Omega-3 fatty acid (n-3) has been used beneficially to attenuate muscle atrophy linked to sepsis and cachexia; however, its effect on dexamethasone-induced muscle atrophy has not been evaluated. Objectives. We evaluated whether $\mathrm{n}-3$ supplementation could mitigate the development of dexamethasone-induced muscle atrophy. Methods. Two groups of Wistar rats were orally supplemented with n-3 or vehicle solution for 40 days. In the last 10 days, dexamethasone, or saline solution, was administrated establishing four groups: control, dexamethasone, $\mathrm{n}-3$, and dexamethasone + $\mathrm{n}-3$. The cross-sectional areas of muscle fibers, gene expression (MyoD, Myogenin, MuRF-1, and Atrogin-1), and protein expression (Akt, GSK3 $\beta$, FOXO3a, and mTOR) were assessed. Results. Dexamethasone induced a significant loss in body and muscle weight, atrophy in type $2 \mathrm{~B}$ fibers, and decreased expression of P-Akt, P-GSK3 $\beta$, and P-FOXO3a. N-3 supplementation did not attenuate the negative effects of dexamethasone on skeletal muscle; instead, it caused atrophy in type 1, $2 \mathrm{~A}$, reduced the expression of Myogenin, and increased the expression of Atrogin-1. Conclusion. Food supplements containing n-3 are usually healthful, but they may potentiate some of the side effects of glucocorticoids.
\end{abstract}

\section{Introduction}

Muscle atrophy is the loss of muscle mass resulting from a reduction in muscle fiber area or density due to a decrease in protein synthesis and an increase in muscle protein breakdown; these processes activate two major systems: the proteasomal (ubiquitin-proteasome system or UPS) and the autophagic-lysosomal system [1-3]. Many conditions are associated with skeletal muscle atrophy, such as prolonged fasting, inactivity, or pathological conditions such as sepsis, cachexia, AIDS, cancer, and glucocorticoid treatment among others $[1,2]$.

Glucocorticoids are one of the most widely prescribed therapeutic compounds, used in the treatment of inflammatory, autoimmune, lymphoproliferative, and neuromuscular disorders $[4,5]$. Despite its benefits in inflammatory responses, treatment with glucocorticoids harms the skeletal muscle [6].
Many studies have shown that glucocorticoids not only cause muscle atrophy through the IGF-1/PI-3K/Akt/mTOR and myostatin/Smad2/3 pathways $[7,8]$, but also through the regulation of muscle transcription factors, atrogenes, and cathepsins $[8,9]$. Some of these mechanisms involve the reduction in mTOR activity induced by an increase of REDD1 (regulated in development and DNA damage responses 1) [10], and an increase in the GSK $3 \beta$ protein. Increased levels of GSK $3 \beta$ are associated with the proteasomal system leading to increased protein degradation and decreased protein synthesis [11]. Glucocorticoids reduce the activity of Akt, which, among other functions, acts as a negative regulator of the forkhead transcription factor (FOXO). FOXOs activation leads to a rapid protein degradation and stimulates the transcription of several components of the lysosomal and ubiquitin-proteasome systems [12-16]. Activated FOXO1 and FOXO3a lead to the upregulation of Atrogin-1, MuRF-1, $R E D D 1$, and $4 E B P 1$, which lead to muscle atrophy [17]. 
Polyunsaturated fatty acids (PUFAs) are considered beneficial food supplements to human health, particularly effective in the cardiovascular and central nervous systems [1820]. Two particular PUFAs families the Omega-3 (n-3) and Omega-6 (n-6) fatty acids are the most consumed worldwide and are linked to effects widely discussed in the scientific community. The $\mathrm{n}-3$ as supplement is commercialized worldwide with free access of the population in capsules ranging from 500-2000 $\mathrm{mg}$ of fish oil extract per capsule. The World Health Organization (WHO) considers 0.25 to $2 \mathrm{~g}$ of EPA/DHA per day as part of a healthy diet [21], and the US Food and Drug Administration (FDA) recommends a maximum intake of $3 \mathrm{~g}$ per day of n-3 (EPA/DHA) [22], equivalent to $50 \mathrm{mg} / \mathrm{kg} /$ day in a $60 \mathrm{~kg}$ person. The American Heart Association (AHA) recommends the intake of 2 to $4 \mathrm{~g}$ of EPA/DHA per day to patients with increased levels of serum triglycerides, provided as capsules under a physician's care [23]. The n-3 PUFAs such as EPA (eicosapentaenoic acid), DHA (docosahexaenoic acid), and ALA ( $\alpha$-linolenic acid) are incorporated into the cell membrane after absorption and can modulate various cellular functions, such as signaling and gene expression [24] and decrease the activity of certain UPS components as seen in cancer cachexia [25]. However, to our knowledge, the effects of n-3 PUFA on glucocorticoidinduced muscle atrophy have not been tested.

This study evaluated the effects of n-3 PUFA (capsule formulation) on the development of dexamethasone-induced muscle atrophy through histological analysis, expression of genes involved in protein synthesis and degradation, and assessment of expression of proteins involved in the IGF-1/PI3k/Akt/mTOR pathway.

\section{Methods}

2.1. Animal Treatment. We used in this study 24 male Wistar rats, aged between 10 to 12 weeks, with body weights from 330 to 370 grams. All experiments were performed according to the National Institutes of Health (NIH) guidelines on care, handling, and use of laboratory animals and approved by the local ethics committee. Animals were housed in four cages (6 animals each) and placed under controlled light (12hour light/dark cycle) and temperature $\left(25^{\circ} \mathrm{C}\right)$ conditions. Animals were fed ad libitum with a standard commercial diet (Nuvilab CR1) with an approximated composition of $22.0 \%$ crude protein, $4.5 \%$ ether extract, $8.0 \%$ fibrous matter, $1.4 \%$ calcium, and $0.8 \%$ phosphorus and amino acids (DLMethionine $300 \mathrm{mg}$, lysine $100 \mathrm{mg}$ ).

In the first part of the study, 24 animals were divided into two initial groups: 12 animals were supplemented daily for 40 days, via gavage (v.g.), with n-3 capsules (Proepa, Ache laboratories) diluted in vehicle solution (tween-20 and ultrapure water) and the other 12 animals received the same volume of vehicle solution for the same period of time. According to the manufacturer, each n-3 capsule contained energetic value $(9.4 \mathrm{Kcal}=39.5 \mathrm{KJ})$; total fats $(1.0 \mathrm{~g})$; monounsaturated fats $(0.3 \mathrm{~g})$; polyunsaturated fats $(0.4 \mathrm{~g})$; eicosapentaenoic acid (180 mg), and docosahexaenoic acid (120 mg). The amount of EPA and DHA administrated was adjusted in vehicle solution to the dosage of $100 \mathrm{mg} / \mathrm{kg} /$ day per animal. After day 30, six animals from each group received $5 \mathrm{mg} / \mathrm{kg} /$ day of subcutaneous (sc.) dexamethasone (Decadron, Ache) for 10 days to induce muscle atrophy, along with n-3 supplementation. The six remaining animals in each group received saline solution as a control. The experimental protocols utilized in these four groups are summarized as DX + n-3 group [n-3 PUFA v.g. (40 days) + dexamethasone sc. (last 10 days)], n-3 group [n-3 PUFA v.g. (40 days) + saline solution sc. (last 10 days)], DX group [vehicle solution v.g. (40 days) + dexamethasone sc. (last 10 days)], and CT group [vehicle solution v.g. (40 days) + saline solution sc. (last 10 days)]. The animals were weighed on days $1,10,20,30,32,34,36$, and 40.

Animals were euthanized after 40 days by intraperitoneal injection with sodium pentobarbital $(30 \mathrm{mg} / \mathrm{kg})$. Bilateral gastrocnemius (GA) and tibialis anterior (TA) muscles were collected and weighed. Right-side samples were mounted in Tissue-Tek, immersed in isopentane, and cooled in liquid nitrogen for histological analysis. The remaining muscles were frozen in liquid nitrogen and stored at $-80^{\circ} \mathrm{C}$ for subsequent gas chromatography and extraction of protein and RNA.

\subsection{Analysis of PUFAs and Fat Content by Gas Chromatogra-} phy. GA muscle samples were analyzed by gas chromatography to evaluate PUFAs and fat content. Fat extraction was carried out by the Bligh and Dyer methodology [26] according to Iverson et al. (2001) [27]. Initially, $125 \mathrm{mg}$ of samples was homogenized (Ultra-turrax, IKA T10 Basic) with a mixture containing chloroform $(125 \mu \mathrm{L})$ and methanol $(200 \mu \mathrm{L})$. The solution was homogenized again with chloroform $(125 \mu \mathrm{L})$ and saline $(125 \mu \mathrm{L}$ of $0.88 \% \mathrm{NaCl})$. The final emulsion was centrifuged at $13,000 \mathrm{~g}$ for 5 minutes at $25^{\circ} \mathrm{C}$. The upper phase was removed and the lower phase evaporated under nitrogen stream. Fat samples were derivatized using the technique of direct esterification described by Shirai et al. (2005) [28] and their composition was determined by gas chromatograph (Agilent 7890 A GC System, Agilent Technologies, Inc., Santa Clara, USA). A fused silica capillary column (J\&W DB-23 Agilent 122-236; $60 \mathrm{~m} \times 250 \mathrm{~mm}$ inner diameter) was used for injection. High-purity helium was used as the carrier gas at a flow rate of $1 \mathrm{~mL} /$ minute and a split injection of $50: 1$. The programming of column temperature was starting at $80^{\circ} \mathrm{C}$; a gradient step at a heating rate of $5^{\circ} \mathrm{C} /$ minute to reach $175^{\circ} \mathrm{C}$; a gradient step at a heating rate of $3^{\circ} \mathrm{C} /$ minute to reach $230^{\circ} \mathrm{C}$; and maintenance of $230^{\circ} \mathrm{C}$ for 5 minutes. The injector and detector (FID) temperatures were $250^{\circ} \mathrm{C}$ and $280^{\circ} \mathrm{C}$, respectively. The fatty acids were identified by comparing their retention times to those of four purified standard mixtures of fatty-acid methyl esters (Sigma Chemical Co.: 4-7801, 47085-U, 49453-U, and 47885-U). The results were expressed as percentages of total fatty acids. Muscle tissue contents of total PUFAs and fat were determined. DX group muscles were not evaluated because this group did not receive n-3 supplementation. 
2.3. Analysis of Cross-Sectional Areas in the Skeletal Muscle. Cross-sectional areas from muscle fibers (types 1,2A, and 2B) were calculated and analyzed. TA muscles were sectioned in a Leica CM3000 cryostat $(8 \mu \mathrm{m})$ and sections were treated using the metachromatic dye-ATPase method (mATPase) according to Ogilvie and Feeback (1990) [29]. Slides with dried frozen sections were placed in a preincubation solution composed of distilled water $(475 \mathrm{~mL})$, dehydrated potassium acetate $(2.45 \mathrm{~g})$, and calcium chloride $(1.30 \mathrm{~g})$ at $\mathrm{pH} 4.5$ for 2 minutes; slides were subsequently rinsed in Tris buffer. Slides were then incubated for 25 minutes in an incubation solution composed of distilled water $(30 \mathrm{~mL})$, potassium chloride (185 mg), ATP, disodium salt $(76 \mathrm{mg})$, dehydrated calcium chloride, $(0.18 \mathrm{M}=5 \mathrm{~mL})$, and Sigma 221 buffer $(1.5 \mathrm{M} \mathrm{2-}$ amino-2-methyll-propanol) $(3.35 \mathrm{~mL})$ at $\mathrm{pH}$ 9.4. Slides were rinsed by dipping in three changes of $1 \%$ calcium chloride solution, stained with $1 \%$ aqueous toluidine blue for 10 seconds, and immediately rinsed in distilled water. Images of stained muscle sections were acquired on an Olympus AX70 light microscope (Olympus Melville, NY). Cross-sectional areas from types $1,2 \mathrm{~A}$, and $2 \mathrm{~B}$ fibers, from five slides per animal (300 to 400 fibers/animal), were measured using the Image J software (NIH).

2.4. Immunoblot Expression of $m T O R, A k t, G S K 3 \beta$, and FOXO3a Proteins. The mTOR, Akt, GSK3 $\beta$, and FOXO3a protein levels were assessed by quantitative Western blot analysis in GA muscle tissue samples collected as described. Tissues were homogenized in a Potter homogenizer in lysing buffer containing $1 \%$ protease and phosphatase inhibitor cocktail (Sigma-Aldrich; P5726 and A-1153, resp.), $1 \mathrm{mM}$ EDTA (Sigma), and 1\% NP40 (Sigma) diluted in phosphatebuffered saline (PBS, $\mathrm{pH} 7.4$ ) and stored at $-80^{\circ} \mathrm{C}$ until use. Total protein concentrations were quantified by Bradford method (1976) [30]. Samples with up to 50 to $100 \mu \mathrm{g}$ of total protein were submitted to Western blot. The primary antibodies used were Akt (1:2,000, Cell Signaling \#4691), PAkt (1:2,000, Cell Signaling \#4060, Ser473); mTOR (1:500, Cell Signaling \#2972), P-mTOR (1:500, Cell Signaling \#2971, Ser2448), GSK3 $\beta$ (1:2,000, Cell Signaling \#9315), P-GSK3 $\beta$ (1:2,000, Cell Signaling \#9322, Ser9), FoXO3a (1:500, Cell Signaling \#2497), P-FoXO3a (1:500, Cell Signaling \#9466, Ser253), and $\alpha$-tubulin $(1: 30,000$, Hybridoma bank) in $5 \%$ BSA/TBS-T. The secondary conjugated antibodies were IgGECL anti-rabbit $(1: 10,000, \mathrm{KPL})$ or anti-mouse $(1: 6,000$, Santa Cruz Biotechnology). Finally, membranes were incubated with Western Lightning Chemiluminescence Reagent Plus (PerkinElmer Life Science, USA) for $1 \mathrm{~min}$ and exposed to an X-ray film (Hyperfilm ECL, Amersham Biosciences, USA) for visualization of the protein bands. The films were scanned (HP Scanjet G4000 series) and protein levels were quantified by densitometry using a computer-assisted image analyzer through the Image J software (version $1.43 \mathrm{u}$, National Institute of Health, USA). The density values were normalized by the $\alpha$-tubulin density values.

2.5. Expression of MyoD, Myogenin, REDD1, REDD2, MuRF1, and Atrogin-1 Measured by Quantitative PCR. Total RNA was extracted from GA muscle samples with TRIZOL reagent (Invitrogen), according to the manufacturer's instructions. RNA quantity and integrity were assessed by spectrophotometry (Nanodrop, Thermo Scientific, USA) and microfluidicsbased electrophoresis (Agilent 2100 Bioanalyzer, Agilent Technologies, USA), respectively. RNA samples with 260/280 OD ratios of approximately 2.0 and RIN $>7.0$ were used in the quantitative PCR (qPCR) reactions. cDNA was synthesized from $1 \mu \mathrm{g}$ of total RNA using TaqMan Reverse Transcription Reagents N808-0234 (Applied Biosystems Life Technologies), according to the manufacturer's instructions.

The qPCR reactions were carried out in duplicate with 50 ng cDNA, SYBR Green PCR master mix (Fermentas), and 800 to $900 \mathrm{nM}$ of each primer in a final volume reaction of $25 \mu \mathrm{L}$ in the Step One Plus device (Applied Biosystems, USA). Real-time PCR was performed to investigate the expression of the following genes: MyoD [31] (forward: $5^{\prime}$-TGTAACAACCATACCCCACTCTC-3', reverse: $5^{\prime}$-AGATTTTGTTGCACTACACAGCA-3'), Myogenin [32] (forward: $5^{\prime}$-CACATCTGTTCGACTCTCTTCT-3'; reverse: $5^{\prime}$-ACCTTGGTCAGATGACAGCTTTA-3' $)$, REDD-1 [33] (forward: $5^{\prime}$-CACCGGCTTCAGAGTCATCA-3'; reverse: $5^{\prime}$ CGGGTCTCCACCACA GAAAT-3'), REDD-2 [33] (forward: $5^{\prime}$-CTTCAGCGTCTGGTGAAATCC- $3^{\prime}$; reverse: $5^{\prime}$ ATGCTGGCCGTGTTCTTACTG-3'), MuRF-1 [34] (forward: $5^{\prime}$-TCGACATCTACAAGCAGGAA-3'; reverse: $5^{\prime}$ CTGTCCTTGGAAGATGCTTT-3'), and Atrogin-1 [34] (forward: $5^{\prime}$-TGAAGACCGGCTACTGTGGAAGAGAC-3'; reverse: $5^{\prime}$-TTGGGGTGAAAGTGAGACGGAG CAG-3'). The results were normalized individually by the expression of GAPDH [35] (forward: 5'-ACGCCAGTAGACTCCACGAC$3^{\prime}$; reverse: $5^{\prime}$-ATGACTCTACCCACGGCAAG-3') and further compared by logarithmic normalization $\left(2^{-\Delta \Delta C T}, A B I\right.$ PRISM 7700 Sequence Detection System protocol; Applied Biosystems).

2.6. Statistical Analysis. Differences between means were analyzed by unpaired Student's $t$-test, whereas differences among means were analyzed by One- or Two-way ANOVA followed by Bonferroni post hoc testing. All analyses were performed using the Graph Pad Prism 5.0 software for Windows (Graph Pad Software, USA). The data are presented as mean \pm S.E.M., with the significance level set at $P<0.05$.

\section{Results}

3.1. n-3 PUFA Does Not Alleviate Body and Muscle Weight Loss or Muscle Atrophy Induced by Dexamethasone. All animals presented appropriate weight gain according to natural growth during the first 30 days of the study with no statistical difference in weight gain between the four experimental groups during this period. A significant difference in body weight became evident on the second day after dexamethasone administration (groups DX and DX $+n-3$ ) (Figure 1). One animal from the DX group died on the fifth day of dexamethasone administration. The mean body weight in the CT group was $356.33 \pm 4.7 \mathrm{~g}$ at the beginning of the study and $427.66 \pm 11.8 \mathrm{~g}$ at the end of the study, indicating 


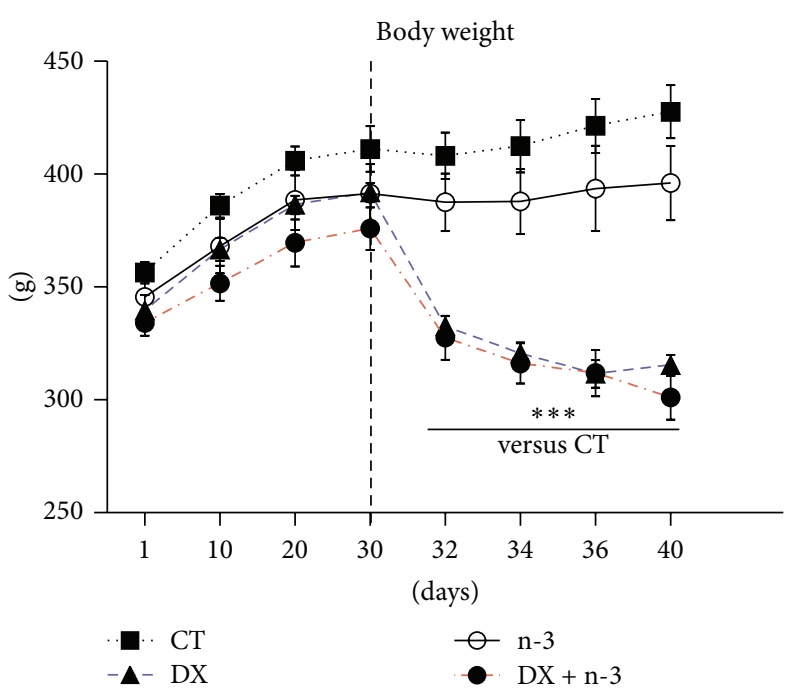

FIGURE 1: Changes in body weight (grams) in animals treated with n-3 PUFA or vehicle for 40 days and dexamethasone or vehicle (last 10 days). The dotted line indicates the start of dexamethasone administration. CT $=$ control group $(n=6), \mathrm{DX}=\operatorname{dexamethasone~group~}(n=5)$, n-3 = n-3 PUFA group $(n=6)$, and DX $+n-3=$ dexamethasone $+n-3$ PUFA group $(n=6)$. Values represent means \pm S.E.M., analyzed by two-way ANOVA repeated measure followed by Bonferroni post hoc test, ${ }^{* * *} P<0.001$.

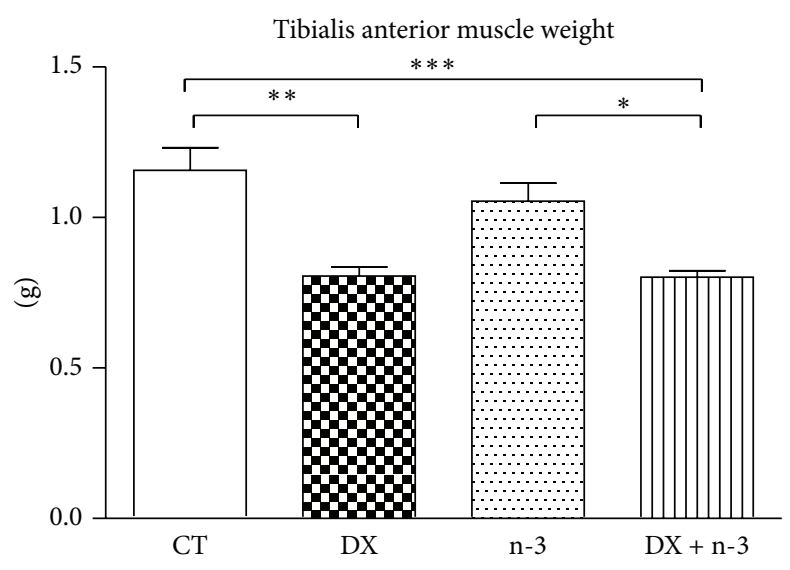

(a)

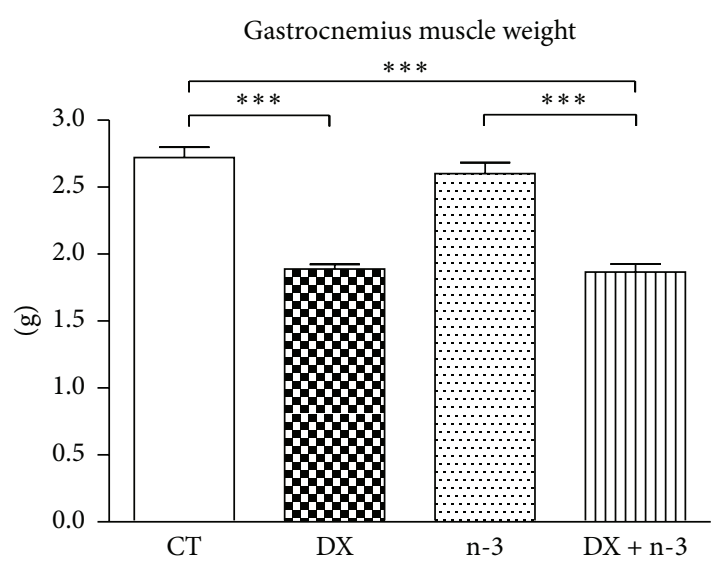

(b)

FIGURE 2: Muscle weights in the DX and DX $+n-3$ groups were significantly decreased compared to the CT group. CT $=$ control group $(n=6)$, DX $=$ dexamethasone group $(n=5), \mathrm{n}-3=\mathrm{n}-3$ PUFA group $(n=6)$, and DX $+\mathrm{n}-3=$ dexamethasone $+\mathrm{n}-3$ PUFA group $(n=6)$. Values represent means \pm S.E.M., analyzed by one-way ANOVA followed by Bonferroni post hoc test, ${ }^{*} P<0.05 ;{ }^{* *} P<0.01$, and ${ }^{* * *} P<0.001$.

a gain of $20.01 \%$. The weight gain in the $n-3$ group was $14.61 \%$ (from $345.5 \pm 8.8 \mathrm{~g}$ to $396.0 \pm 16.4 \mathrm{~g}$ ), which has no statistical difference to CT group. Animals from the DX and DX + n-3 groups showed both body weight loss compared to the initial to the final day of study, corresponding $8.54 \%$ in the DX group (initial weight $339.5 \pm 6.8 \mathrm{~g}$ and final weight $310.5 \pm 5.6 \mathrm{~g}$ ) and $9.88 \%$ in the DX $+\mathrm{n}-3$ group (initial weight $334.00 \pm 5.52 \mathrm{~g}$ and final weight $301.0 \pm 9.8 \mathrm{~g}$ ). Whereas the body weight loss pre- and postdexamethasone administration was of $21.75 \%$ (DX group) and 19.91\% (DX + n-3 group), both significantly decreased compared to CT group $(P<0.001)$. There were no statistical differences in body weight comparing DX to the $\mathrm{DX}+\mathrm{n}-3$ group and comparing CT to the $\mathrm{n}-3$ group.
The TA and GA muscle samples were weighed immediately after euthanasia; the weights of muscle samples from the $\mathrm{DX}$ and DX $+\mathrm{n}-3$ groups was significantly smaller than those from the CT group $(P<0.01$ and $P<0.001$, resp. $)$ (Figure 2$)$. There was no difference in muscle weight comparing CT to the $n-3$ group. These findings indicate that the administration of n-3 did not effectively mitigate the weight loss either in body or muscle tissues induced by dexamethasone.

In the muscle atrophy analysis, we observed that the administration of dexamethasone induced a significant TA muscle atrophy of type $2 \mathrm{~B}$ muscle fibers (fast-twitch), reducing their cross-sectional area by $25.03 \%$ in the DX group and by $32.71 \%$ in the DX $+n-3$ group compared to the CT group 


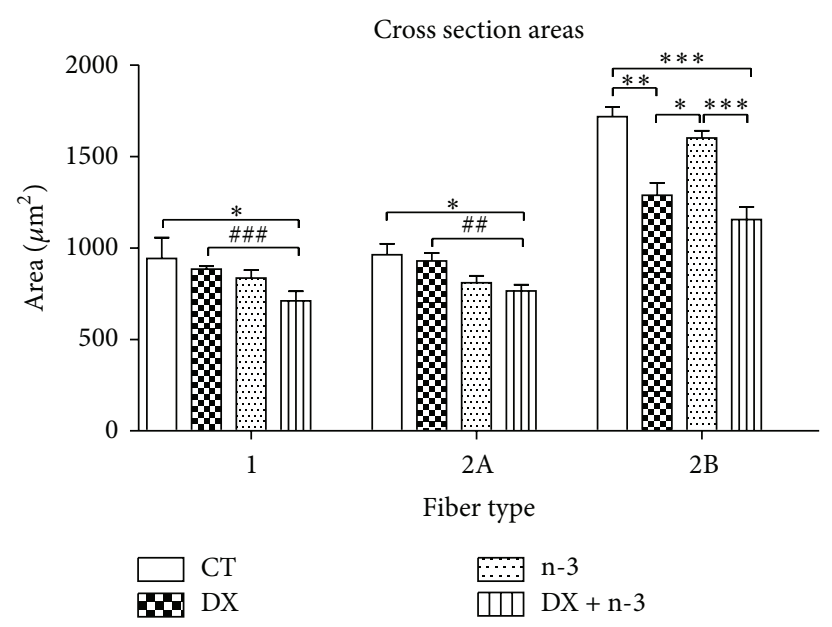

(a)
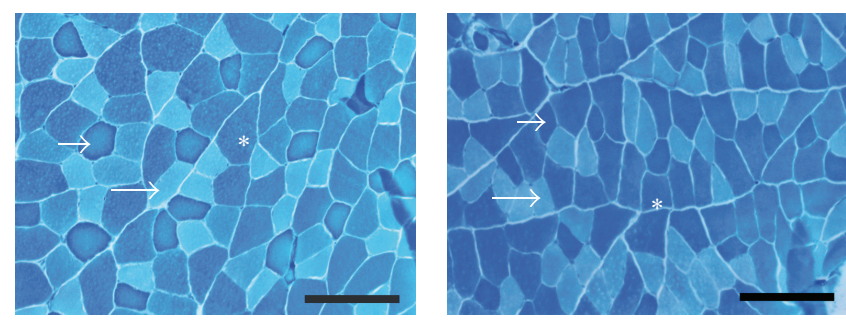

(b)

Figure 3: Means of cross-sectional areas of tibialis anterior muscle fibers (type 1, 2A, and 2B) in rats treated with n-3 PUFA or vehicle for 40 days and dexamethasone or vehicle (last 10 days). (a) Fiber type size distribution; (b) representative mATPase dye histological images of TA muscle from the control group (left), and from the DX $+n-3$ group (right). Small arrow = type 1 fiber; large arrow = type $2 \mathrm{~A}$ fiber; asterisk = type 2B fiber. Scale bar $(100 \mu \mathrm{m})$. CT $=$ control group $(n=6), \mathrm{DX}=$ dexamethasone group $(n=5), \mathrm{n}-3=\mathrm{n}-3$ PUFA group $(n=6)$, and DX + $\mathrm{n}-3=$ dexamethasone $+\mathrm{n}-3$ PUFA group $(n=6)$. Values represent means \pm S.E.M., analyzed by One-way ANOVA $\left({ }^{*}\right)$ followed by Bonferroni post hoc test or unpaired Student's $t$-test $\left({ }^{\#}\right),{ }^{*} P<0.05$; $^{* *}$ or ${ }^{\# \#} P<0.01$, and ${ }^{* * *}$ or ${ }^{\# \# \#} P<0.001$.

$(P<0.01$ and $P<0.001$, resp. $)$. In addition, the DX $+\mathrm{n}-3$ group showed a significant muscle atrophy of type 1 and $2 \mathrm{~A}$ muscle fibers compared to the CT $(24.66 \%$ and $20.53 \%$, resp.) $(P<0.05)$ and to the DX group $(19.62 \%$ and $17.95 \%$ in fibers 1 and 2 A, resp. $)(P<0.001$ and $P<0.01$, resp.), (Figures 3(a) and $3(\mathrm{~b}))$. These findings confirmed that the administration of dexamethasone induces atrophy, preferentially in type $2 \mathrm{~B}$ muscle fibers. In addition, the concomitant administration of n-3 PUFA induced atrophy in muscle fiber types that are usually more resistant to atrophy induced by dexamethasone, such as type 1 and $2 \mathrm{~A}$ fibers.

3.2. n-3 PUFA Induces an Increase in PUFA and ALA and a Decrease in Fat and AA in Skeletal Muscles. PUFAs content increased by $9.17 \%$ and fat content decreased by $12.63 \%$ in the n-3 group, showing a significant elevation compared to the CT group $(P<0.05)$. Similar increase in PUFAs and decrease in fat content was observed in the $\mathrm{DX}+\mathrm{n}-3$ group compared to the CT group, $(+6.00 \%$ and $-8.21 \%$, resp. $)(P<0.05)$ (Figure 4(a)).

We observed a significant decrease in the arachidonic acid (AA) content in the $n-3$ and DX $+n-3$ groups compared to the CT group $(P<0.001)$ (Figure 4(b)), and the $\alpha$ linolenic acid (ALA) content was significantly increased in the $\mathrm{n}-3$ group compared to the CT group $(P<0.01)$ with a mild increase in the DX $+n-3$ group compared to the CT group $(P<0.05)$ (Figure $4(\mathrm{c})$ ). These findings indicated that the oral administration of n-3 PUFA was effective for the incorporation of PUFAs in the skeletal muscle.

3.3. The Concomitant Administration of Dexamethasone and n-3 PUFA Induces Suppression of Muscle Transcriptional Factors. The effects of dexamethasone and n-3 PUFA administration on muscle regeneration were evaluated through the expression of muscle transcriptional factors. The expression of $M y o D$ was increased significantly in the n-3 group only when compared to the DX $+\mathrm{n}-3$ group $(P<0.05)$ (Figure 5(a)), suggesting that dexamethasone abrogated the expression of $M y o D$ through interaction with n-3. Conversely, Myogenin expression was significantly decreased in the $\mathrm{DX}+\mathrm{n}-3$ group in comparison to the CT group $(P<$ 0.05 ) (Figure 5(b)). In DX group, there were no statistical differences in the expressions of MyoD or Myogenin as observed in DX $+n-3$ group. These results suggest that 


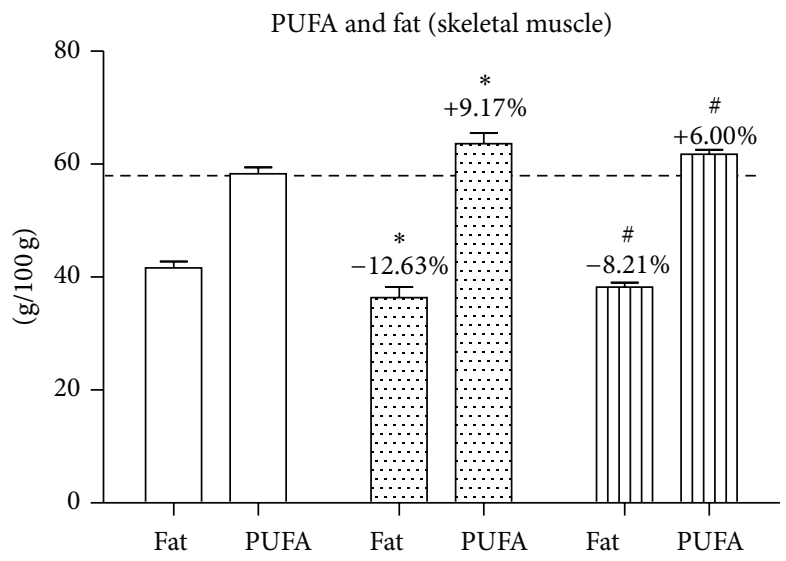

(a)

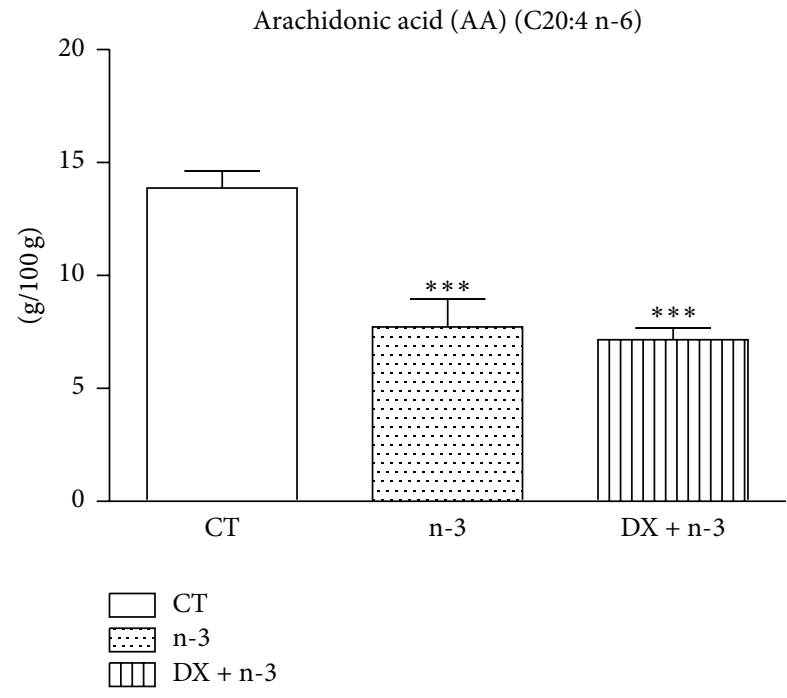

(b)

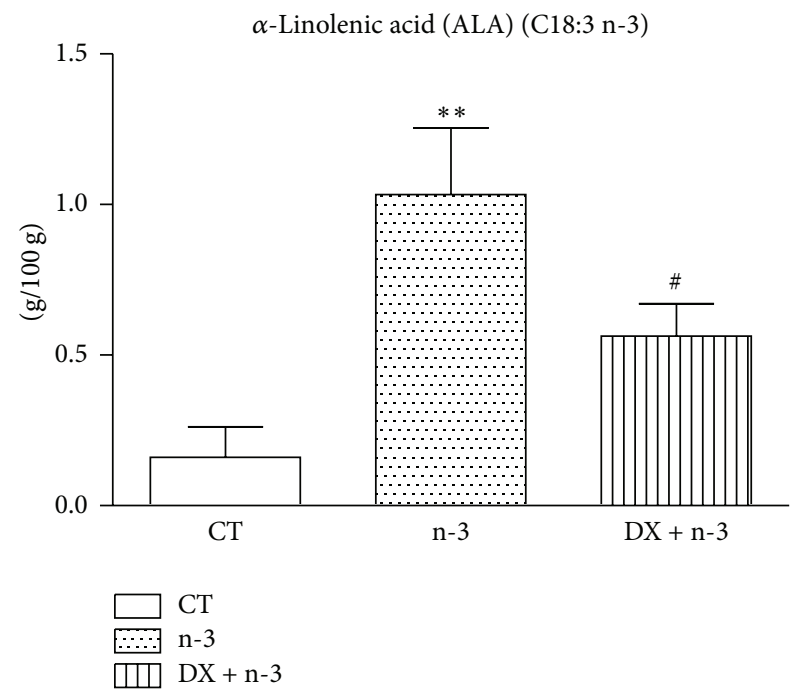

(c)

FIGURE 4: Gas chromatography of GA muscle samples from rats treated with n-3 PUFA or vehicle for 40 days and dexamethasone or vehicle (last 10 days). (a) Percentages of total fat and PUFAs per experimental group. Percentages above the bar indicate decrease or increase in PUFA and fat content compared to the same type of fatty acid in the CT group. ((b) and (c)) percentages of arachidonic and $\alpha$-linolenic acids, respectively. CT $=$ control group $(n=6), \mathrm{n}-3=\mathrm{n}-3$ PUFA group $(n=6)$, and DX $+\mathrm{n}-3=$ dexamethasone $+\mathrm{n}-3$ PUFA group $(n=6)$. Statistical analysis is in comparison with the CT group. Values represent means \pm S.E.M., analyzed by one-way ANOVA $\left({ }^{*}\right)$ followed by Bonferroni post hoc test or Student's $t$-test $\left({ }^{\#}\right),{ }^{*}$ or ${ }^{\#} P<0.05 ;{ }^{* *} P<0.01$ and ${ }^{* * *} P<0.001$.

the administration of n-3 PUFA together with dexamethasone may affect the muscular regeneration process.

\subsection{Dexamethasone Associated with n-3 PUFA Induces Higher} Atrogin-1 Expression in Muscle Fibers Than Dexamethasone Alone. We evaluated the expression of the Atrogin-1 and MuRF-1 atrogenes after dexamethasone and n-3 administration. Both genes showed increased expression in the DX + n-3 group compared to the CT group $(P<0.01$ and $P<0.05$, resp.), as well as in the DX group in MuRF-1 expression $(P<$ $0.01)$. The $\mathrm{n}-3$ group did not show any increase in atrogenes expression (Figures 5(c) and 5(d)). The expression of MuRF-1 in the DX $+n-3$ group was 2.74-fold higher than DX group (not statistically different), and in Atrogin-1 expression was 3.46-fold higher $(P<0.05)$. The expression of REDD2 genes was increased significantly only in the DX group compared to the CT group $(P<0.05)$ without any increase in $\mathrm{DX}+\mathrm{n}-3$ group (Figure 5(e)). No significant difference in REDD1 expression was observed between the groups (data not shown). These data suggest that dexamethasone administration may affect REDD2 and atrogenes expression in skeletal muscles and that the concomitant administration of n-3 PUFA can increase this effect in Atrogin-1 expression.

3.5. Dexamethasone Induces a Decrease in Akt, GSK3- $\beta$, and FOXO3a Phosphorylation. We evaluated the phosphorylated $(\mathrm{P})$, total (t), and phosphorylated/total ratio forms of Akt, GSK $3 \beta$, FOXO3a, and mTOR proteins in GA muscle samples to assess protein expression in the IGF-1/PI-3K/Akt/mTOR pathway (Figures 6 and 7). 


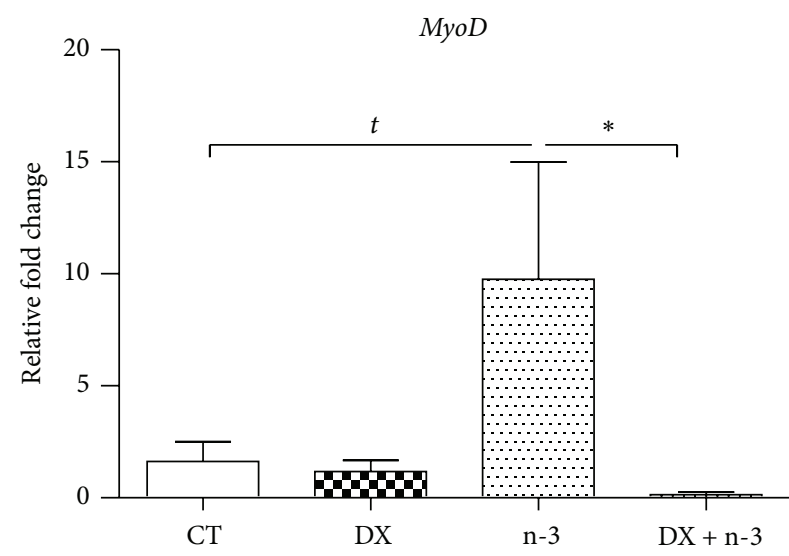

(a)

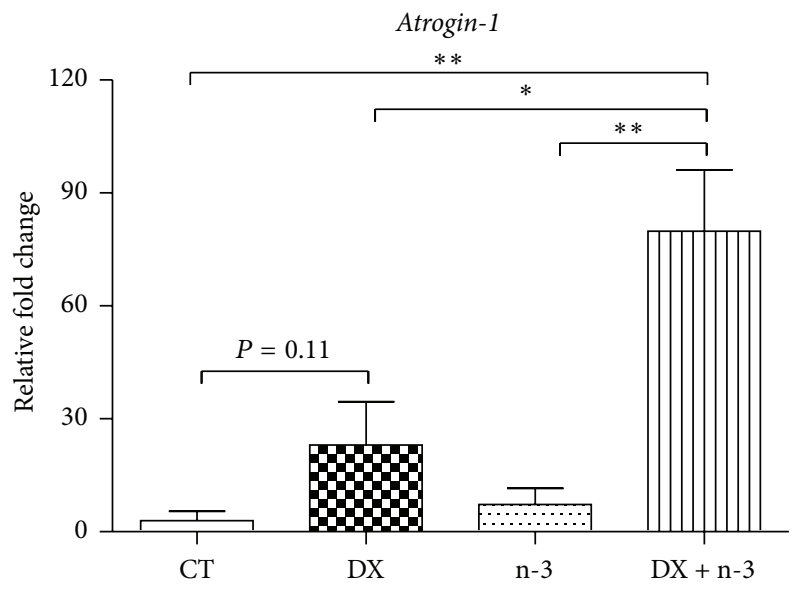

(c)

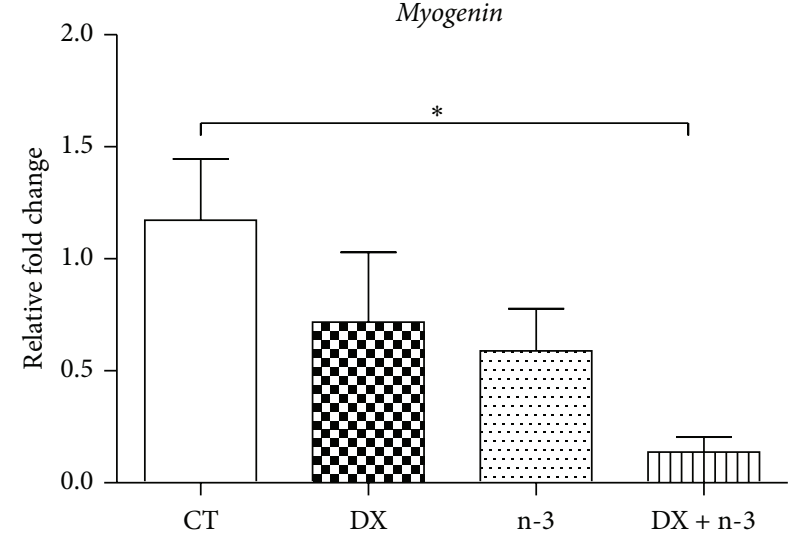

(b)

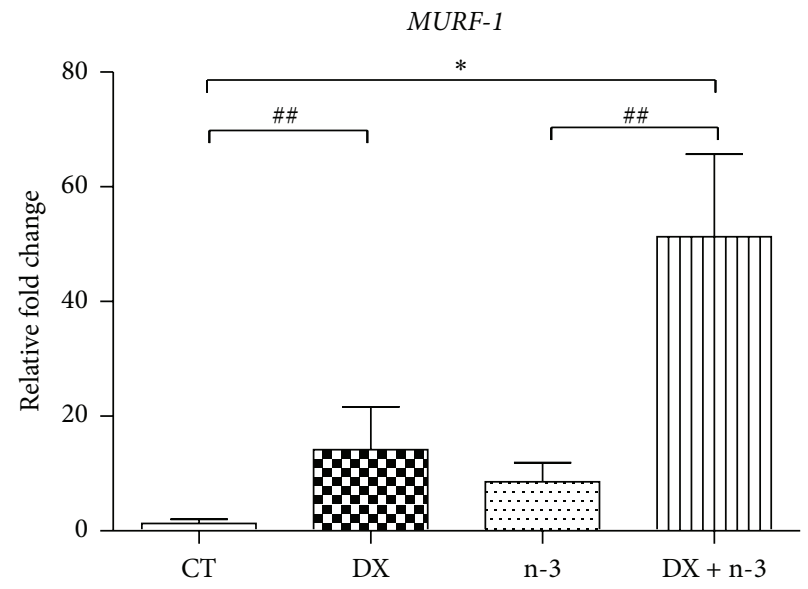

(d)

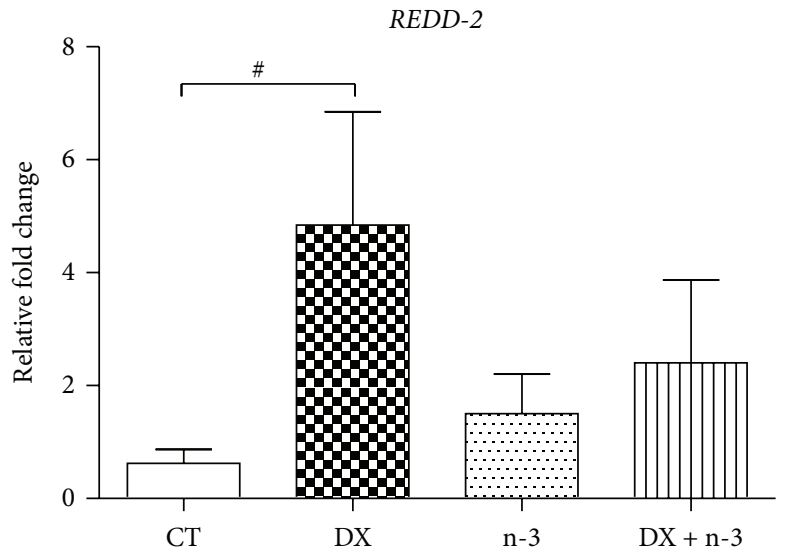

(e)

FIGURE 5: Quantitative PCR results of gene expression in GA muscle samples from rats treated with n-3 PUFA or vehicle for 40 days and dexamethasone or vehicle (last 10 days). Relative fold change values for (a) MyoD, (b) Myogenin, (c) Atrogin-1, (d) MuRF-1, and (e) REDD2. Results are represented as means \pm S.E.M. CT $=$ control group $(n=6), \mathrm{DX}=$ dexamethasone group $(n=5), \mathrm{n}-3=\mathrm{n}-3$ PUFA group $(n=6)$, and DX $+n-3=$ dexamethasone + n-3 PUFA group $(n=6)$. Values represent means \pm S.E.M., analyzed by one-way ANOVA $\left({ }^{*}\right)$ followed by Bonferroni post hoc test or Student's $t$-test $\left({ }^{\#}\right),{ }^{*}$ or ${ }^{\#} P<0.05$ and ${ }^{\# \#} P<0.01$. 


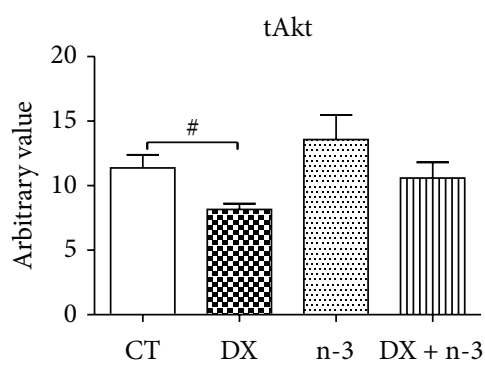

(a)

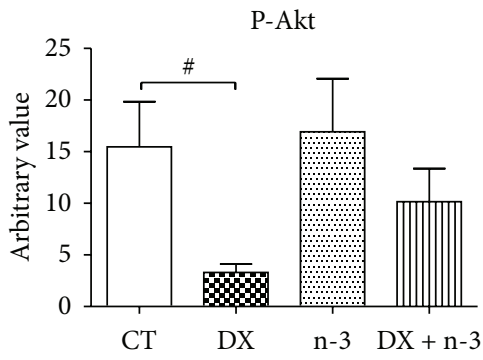

(c)

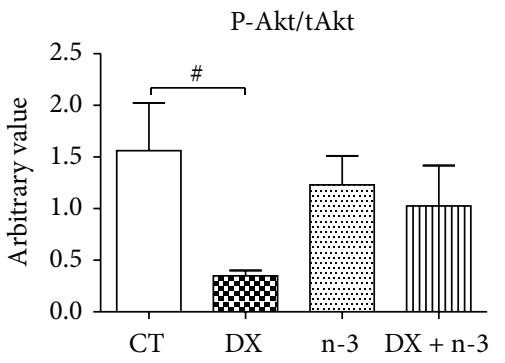

(e)

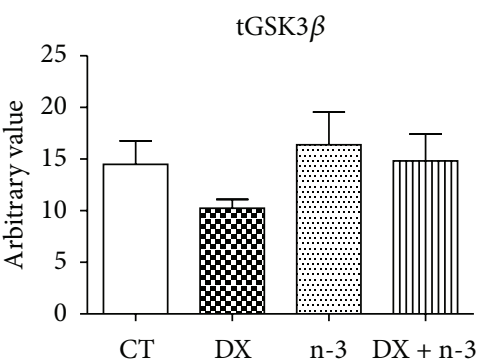

(b)

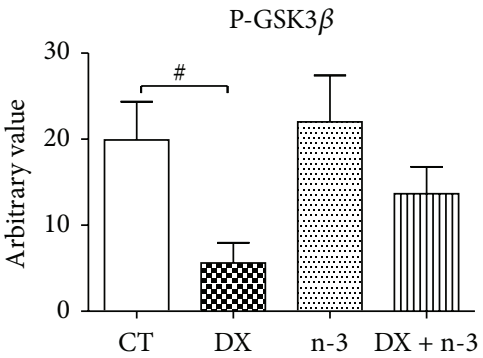

(d)

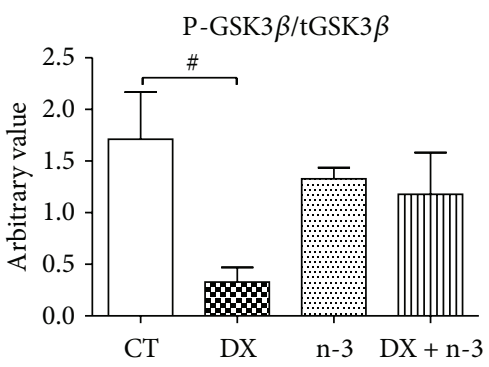

(f)

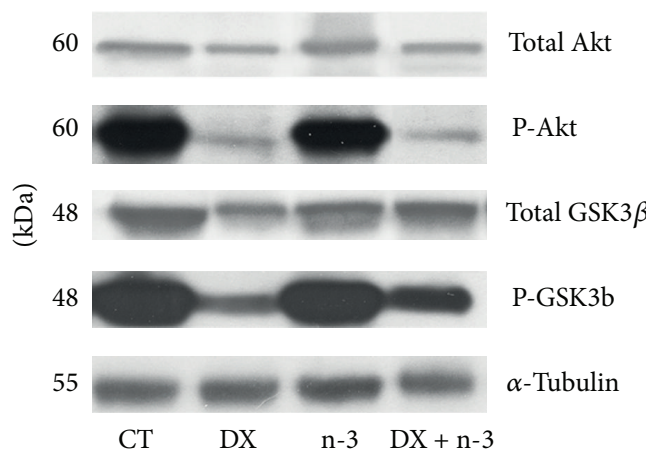

(g)

FIGURE 6: Protein expression in GA muscle samples from rats treated with n-3 PUFA or vehicle for 40 days and dexamethasone or vehicle (last 10 days). Relative optical density of total Akt (tAkt) and phosphorylated Akt (P-Akt) ((a) and (c)), total GSK3 $\beta$ (tGSK3 $\beta$ ) and phosphorylated GSK3 $\beta$ (P-GSK3 $\beta)((\mathrm{b})$ and (d)), and tAkt/P-Akt and tGSK3 $\beta / \mathrm{P}-\mathrm{GSK} 3 \beta$ ratios ((e) and (f), resp.). Bands representing tAkt, P-Akt, tGSK3, and P-GSK3 $\beta$ are illustrated in $(\mathrm{g}) . \alpha$-Tubulin $(55 \mathrm{kDa})$ was used as control. The numbers represent the mean \pm S.E.M. CT $=$ control group $(n=6), \mathrm{DX}=$ dexamethasone group $(n=5), \mathrm{n}-3=\mathrm{n}-3$ PUFA group $(n=6)$, and DX $+\mathrm{n}-3=$ dexamethasone $+\mathrm{n}-3$ PUFA group $(n=6)$. Values represent means \pm S.E.M., analyzed by Student's $t$-test, ${ }^{\#} P<0.05$. 


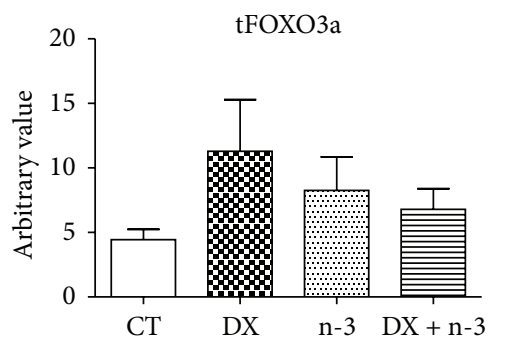

(a)

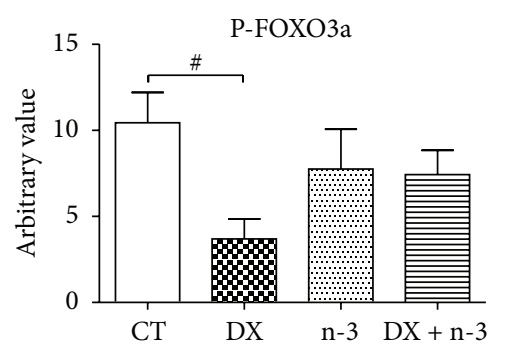

(c)

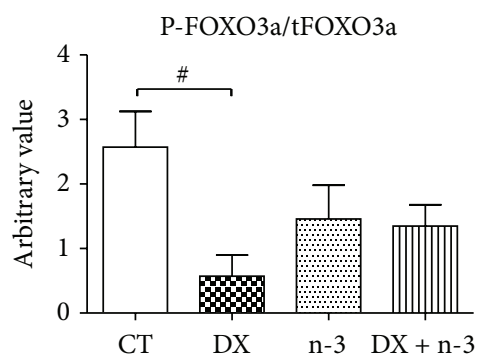

(e)

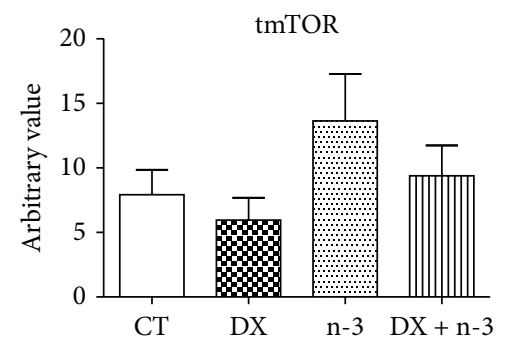

(b)

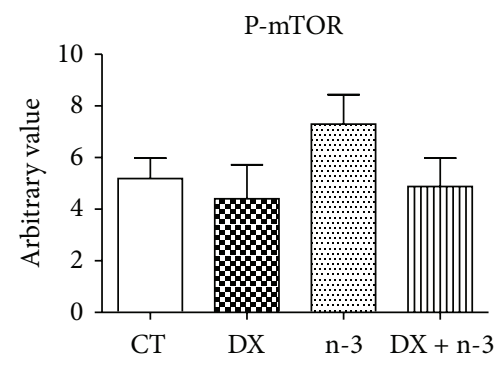

(d)

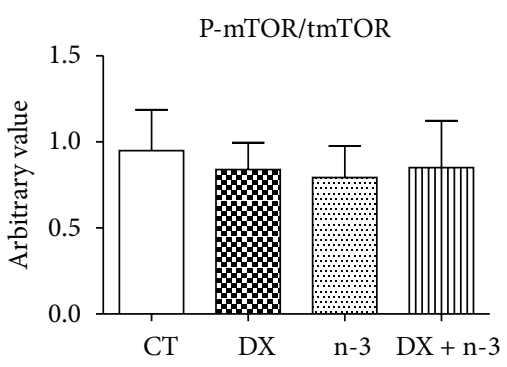

(f)

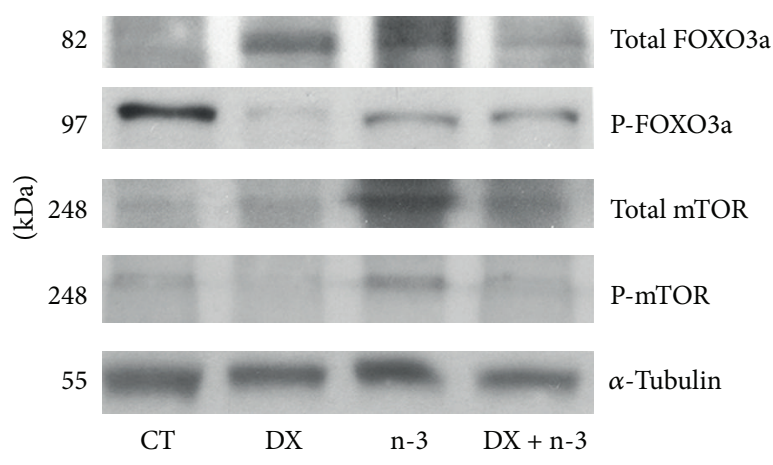

(g)

FIGURE 7: Protein expression in GA muscle samples from rats treated with n-3 PUFA or vehicle for 40 days and dexamethasone or vehicle (last 10 days). Relative optical density of total FOXO3a (tFOXO3a) and phosphorylated FOXO3a (P-FOXO3a) ((a) and (c)), total mTOR (t-mTOR) and phosphorylated (P-mTOR) ((b) and (d)), and P-FOXO3a/tFOXO3a and P-mTOR/tmTOR ratios ((e) and (f), resp.). Bands representing tFOXO3a, P-FOXO3a, t-mTOR, and P-mTOR are illustrated in (g). $\alpha$-Tubulin ( $55 \mathrm{kDa})$ was used as control. The numbers represent the mean \pm S.E.M. CT $=$ control group $(n=6), \mathrm{DX}=$ dexamethasone group $(n=5), \mathrm{n}-3=\mathrm{n}-3$ PUFA group $(n=6)$, and DX $+\mathrm{n}-3=$ dexamethasone + n-3 PUFA group $(n=6)$. Values represent means \pm S.E.M., analyzed by Student's $t$-test, ${ }^{\#} P<0.05$. 
In the DX group, the $\mathrm{t}-\mathrm{AKT}, \mathrm{P}-\mathrm{Akt}$, and P-GSK $3 \beta$ expression, as well as, P-Akt/tAkt and P-GSK $3 \beta / \mathrm{tGSK} 3 \beta$ ratios were significantly decreased compared to the CT group $(P<0.05)$ (Figures 6(a), 6(c), 6(d), 6(e), and 6(f)).

The P-FOXO3a and P-FOXO3a/tFOXO3a ratio were significantly decreased $(P<0.05)$ compared to the CT group (Figures $7(\mathrm{c}$ ), and $7(\mathrm{e})$ ). No significant difference was observed in mTOR expression between the four groups (Figures 7(b), 7(d), and 7(f)).

$\mathrm{DX}+\mathrm{n}-3$ group showed intermediate values in the expression of P-Akt and P-FOXO3a between CT and DX groups, however, with no statistical difference comparing both groups. The expression of all forms of Akt, GSK3 $\beta$, mTOR, and FOXO3a was not affected in the groups supplemented with $n-3$. These findings suggest that the phosphorylation of Akt, GSK3 $\beta$, and FOXO3a is inhibited by dexamethasone administration, and that the n-3 supplementation, apparently, contributes to attenuate these protein changes.

\section{Discussion}

Some studies have shown that EPA and n-3 PUFA supplementation can alleviate muscle atrophy related to cancer, fasting, and septicemia [36-38]. Therefore, we sought to verify whether n-3 would influence the development of muscle atrophy induced by dexamethasone. We observed that dexamethasone administration induced significant loss of body and muscle weight and caused important muscle atrophy in type $2 \mathrm{~B}$ fibers in rats and that the concomitant supplementation of n-3 did not attenuate these alterations.

Other studies have shown that $n-3$ is absorbed effectively by skeletal muscles when administrated orally [39-41]. In our study, the gas chromatography analysis showed that n3 supplementation for 40 days was effective to increase the levels of PUFAs and fatty acids in the skeletal muscle. Thus, we believe that the lack of an effective n-3 attenuation of the dexamethasone-induced muscle atrophy was not related to deficient intestinal absorption of n-3. The dose of $n$ 3 used in our study, similar to that recommended by the US FDA, WHO, and AHA for humans (approximated ratio of $50 \mathrm{mg} / \mathrm{kg} /$ day) [21-23], could not have been effective; however, much higher dose of n-3 (EPA), up to $2.5 \mathrm{~g} / \mathrm{kg} / \mathrm{day}$, has been tried by others [42]. Thus, further studies testing different concentrations of n-3 and dexamethasone are necessary to confirm the effects of n-3 in the skeletal muscle under dexamethasone treatment found in the present study.

The $2 \mathrm{~B}$ muscle fiber atrophy observed in this study has already been described as resulting from dexamethasone administration [43]. Some studies postulate that the high sensitivity of $2 \mathrm{~B}$ fibers is due to the lower content of PGC1 $\alpha$ in this type of fiber [44]. Interestingly, in our study, the concomitant administration of n-3 induced significant muscle atrophy of types 1 and $2 \mathrm{~A}$ muscle fibers, which are usually more resistant to dexamethasone.

According to another study, AA (arachidonic acid) levels stimulate an increase of protein synthesis with release of PGF2 $\alpha$ [45]. Sohal et al., 1992 [46], showed that EPA administration, by changing fatty acid composition of muscle phospholipids, causes a decrease in PGF2 $\alpha$ synthesis, and this change might suppress the rate of protein synthesis on the muscles. AA is the immediate precursor of PGF [47], and EPA/DHA administration is associated with a decrease in levels of AA [48]. In our study we observed a reduction of $42 \%$ in AA levels in the animals treated with n-3 and dexamethasone. This finding might indicate a possible double effect on the muscles of these animals, with a reduction of protein synthesis (by n-3 supplementation, which reduces AA levels) and increase of protein degradation (by dexamethasone administration, which inhibits IGF-1 pathway-related proteins).

Concerning cell signaling mechanisms, Le Foll et al. (2007) [40] showed that the administration of a diet rich in n-3 to rats eliminates insulin's ability to stimulate PI-3K activity and slightly reduces the level of insulin-induced Akt phosphorylation in muscle tissue. The decrease in Akt activity by PI-3k results in a higher activation of transcription factors, such as FOXOs, which might lead to a higher transcription of E3 ligases involved in the muscle atrophy process [14]. According to the literature, the atrophy induced by glucocorticoids occurs through genetic and molecular mechanisms involved in protein degradation, including reduction in Akt, GSK $3 \beta$, P70S6K, and mTOR phosphorylation and increase in the transcription of atrogenes $[49,50]$. In our study, the levels of Akt, GSK3 $\beta$, and FOXO3a phosphorylation were decreased in the DX group; in addition, DX $+n$ 3 group showed higher activation of atrogenes such as Atrogin-1 and MuRF-1. This last finding indicates that the supplementation of n-3 might aggravate the side effects of dexamethasone by affecting upstream pathways of atrogenes activation. Considering that many studies have reported that the administration of $\mathrm{n}-3$ alters the lipid composition in cell membranes $[46,51]$, we might speculate that the n3 supplementation influences dexamethasone-induced muscle atrophy, affecting lipid composition in the sarcolemma and leading to decreased protein synthesis associated with the effects of hypercortisolism on skeletal muscle. These alterations could have modified the activity of receptors in cell membranes, thus altering the activation of intracellular pathways and downstream regulatory proteins, such as those related to the IGF-1/PI3-K/Akt/mTOR pathway, which are compartmentalized and activated through their translocation to the plasma membrane [52]. Nevertheless, these effects are tissue- and cell-specific, because activation or inactivation of Akt by the administration of fatty acids seems to be cell-type dependent [40].

Wang et al., (2006) [10], showed that dexamethasone increases $R E D D 1$ expression in skeletal muscle, which subsequently activates the tuberin-hamartin complex and suppresses mTOR activity. Moreover, the same study observed a decrease in REDD2 mRNA expression. Controversially, Frost et al. (2009) [53] showed that IGF-1, a stimulator of muscle synthesis, increases REDD1 gene and protein expression in skeletal muscle with a paradoxically greater protein synthesis in myotubes expressing more REDD1. The expression of $R E D D 2$, in this same study was decreased by IGF-1 administration. In our study, REDD1 expression did not show consistent changes; however, REDD2 expression 
increased significantly in the DX group compared to the control group.

The reduction in Myogenin levels, observed in the DX + n3 group, is consistent with results from other studies showing that dexamethasone induces many unfavorable conditions to myogenesis, partially through Myogenin inhibition [54, 55], but we did not observe a similar increase in DX group. Another study showed that dexamethasone prevents the formation of TNF-alpha and the release of lipopolysaccharidestimulated IL-6, which influences myoblast proliferation [56]. However, no change was demonstrated in transcription factors related to myogenesis in DX group; a decrease was observed only in DX $+\mathrm{n}-3$ group compared to the CT group. The increased $M y o D$ expression observed in the n-3 group is consistent with results reported by Castillero et al. (2009) [57], which showed an increased MyoD expression in normal and arthritic rats after EPA administration, without changes in Myogenin levels.

In conclusion, this study confirms the deleterious effects of corticosteroids on skeletal muscle. As this type of medicine is commonly used to treat several medical conditions, the identification of drugs or nutritional supplements that could overcome these deleterious effects would be extremely useful in clinical practice. Furthermore, this study highlights that n-3 fatty acids (EPA/DHA) supplementation in rats did not attenuate the negative effects of dexamethasone on skeletal muscle, showing in addition atrophy on type 1 and $2 \mathrm{~A}$ muscle fibers, increased atrogene expression, and reduced Myogenin levels. Thus, food supplements such as n-3, usually considered healthful, may potentiate some of the side effects of glucocorticoids.

\section{Conflict of Interests}

The authors declare that there is no conflict of interests, financial or otherwise, regarding the publication of this paper.

\section{Authors' Contribution}

Alan Fappi, Jessica R. Maximino, and Edmar Zanoteli participated in the conception and design of research; Alan Fappi, Tiago S. Godoy, Vanessa R. Rizzato, and Juliana de C. Neves performed experiments; Alan Fappi, Jessica R. Maximino, and Edmar Zanoteli analyzed data and interpreted results of experiments; Alan Fappi drafted the paper; Alan Fappi, Jessica R. Maximino, Gerson Chadi, Juliana de C. Neves, and Edmar Zanoteli edited and revised the paper; Alan Fappi and Edmar Zanoteli approved the final version of the paper.

\section{Acknowledgments}

The authors thank Dr. Chin Jia Lin and colleagues for their assistance in the real-time PCR assays. Alan Fappi was sponsored by Fundação de Amparo à Pesquisa do Estado de São Paulo (FAPESP 2011/03862-8) and CAPES (Coordenação de Aperfeiçoamento de Pessoal de Nível Superior).

\section{References}

[1] S. Schiaffino, K. A. Dyar, S. Ciciliot, B. Blaauw, and M. Sandri, "Mechanisms regulating skeletal muscle growth and atrophy," The FEBS Journal, vol. 280, no. 17, pp. 4294-4314, 2013.

[2] S. C. Kandarian and R. W. Jackman, "Intracellular signaling during skeletal muscle atrophy," Muscle and Nerve, vol. 33, no. 2, pp. 155-165, 2006.

[3] L. Voisin D Breuillé and L. Combaret C Pouyet D Taillandier E Aurousseau C Obled D Attaix, "Muscle wasting in a rat model of long-lasting sepsis results from the activation of lysosomal, $\mathrm{Ca}^{2+}$-activated, and ubiquitin-proteasome proteolytic pathways," Journal of Clinical Investigation, vol. 97, no. 7, pp. 1610-1617, 1996.

[4] J. K. Clark, W. T. Schrader, and B. W. O’Malley, "Mechanism of steroid hormones," in Willians Textbook of Endocrinology, D. Wilson and D. W. Foster, Eds., pp. 35-90, WB Sanders, Philadelphia, Pa, USA, 1992.

[5] U. C. Reed, "Neuromuscular disorders," Journal of Pediatrics, vol. 78, supplement 1, pp. S89-S103, 2002.

[6] F. J. Kelly and D. F. Goldspink, "The differing responses of four muscle types to dexamethasone treatment in the rat," Biochemical Journal, vol. 208, no. 1, pp. 147-151, 1982.

[7] H. Gilson, O. Schakman, L. Combaret et al., "Myostatin gene deletion prevents glucocorticoid-induced muscle atrophy," Endocrinology, vol. 148, no. 1, pp. 452-460, 2007.

[8] O. Schakman, H. Gilson, S. Kalista, and J. P. Thissen, "Mechanisms of muscle atrophy induced by glucocorticoids," Hormone Research, vol. 72, supplement 1, pp. 36-41, 2009.

[9] K. Komamura, H. Shirotani-Ikejima, R. Tatsumi et al., "Differential gene expression in the rat skeletal and heart muscle in glucocorticoid-induced myopathy: analysis by microarray," Cardiovascular Drugs and Therapy, vol. 17, no. 4, pp. 303-310, 2003.

[10] H. Wang, N. Kubica, L. W. Ellisen, L. S. Jefferson, and S. R. Kimball, "Dexamethasone represses signaling through the mammalian target of rapamycin in muscle cells by enhancing expression of REDD1," Journal of Biological Chemistry, vol. 281, no. 51, pp. 39128-39134, 2006.

[11] K. J. P. Verhees, A. M. W. J. Schols, M. C. J. M. Kelders, C. M. H. O. den Kamp, J. L. J. van der Velden, and R. C. J. Langen, "Glycogen synthase kinase- $3 \beta$ is required for the induction of skeletal muscle atrophy," The American Journal of Physiology: Cell Physiology, vol. 301, no. 5, pp. C995-C1007, 2011.

[12] S. Ciciliot, A. C. Rossi, K. A. Dyar, B. Blaauw, and S. Schiaffino, "Muscle type and fiber type specificity in muscle wasting," The International Journal of Biochemistry and Cell Biology, vol. 5, no. 10, pp. 2191-2199, 2013.

[13] M. Sandri, C. Sandri, A. Gilbert et al., "Foxo transcription factors induce the atrophy-related ubiquitin ligase atrogin-1 and cause skeletal muscle atrophy," Cell, vol. 117, no. 3, pp. 399-412, 2004.

[14] O. Schakman, H. Gilson, and J. P. Thissen, "Mechanisms of glucocorticoid-induced myopathy," Journal of Endocrinology, vol. 197, no. 1, pp. 1-10, 2008.

[15] T. N. Stitt, D. Drujan, B. A. Clarke et al., "The IGF-1/PI3K/Akt pathway prevents expression of muscle atrophy-induced ubiquitin ligases by inhibiting FOXO transcription factors," Molecular Cell, vol. 14, no. 3, pp. 395-403, 2004.

[16] A. Brunet, A. Bonni, M. J. Zigmond et al., "Akt promotes cell survival by phosphorylating and inhibiting a forkhead transcription factor," Cell, vol. 96, no. 6, pp. 857-868, 1999. 
[17] Y. Wu, W. Zhao, J. Zhao et al., "REDD1 is a major target of testosterone action in preventing dexamethasone-induced muscle loss," Endocrinology, vol. 151, no. 3, pp. 1050-1059, 2010.

[18] J. Delgado-Lista, P. Perez-Martinez, J. Lopez-Miranda, and F. Perez-Jimenez, "Long chain omega-3 fatty acids and cardiovascular disease: a systematic review," British Journal of Nutrition, vol. 107, supplement 2, pp. 201-213, 2012.

[19] A. P. Simopoulos, "Omega-6/omega-3 essential fatty acids: biological effects," World review of nutrition and dietetics, vol. 99, pp. 1-16, 2009.

[20] A. P. Simopoulos, "Omega-3 fatty acids in inflammation and autoimmune diseases," Journal of the American College of Nutrition, vol. 21, no. 6, pp. 495-505, 2002.

[21] World Health Organization, "Interim Summary of Conclusions and Dietary Recommendations on Total Fat," http://www.who .int/nutrition/topics/FFA_summary_rec_conclusion.pdf.

[22] FDA, "FDA Announces Qualified Health Claims for Omega-3 Fatty Acids," 2004, http://www.fda.gov/newsevents/newsroom/ pressannouncements/2004/ucm108351.htm.

[23] American Heart Association, "Fish 101," 2014, http://www .heartorg/HEARTORG/GettingHealthy/NutritionCenter/Fish101_UCM_305986_Article.jsp.

[24] M. E. Surette, "The science behind dietary omega-3 fatty acids," Canadian Medical Association Journal, vol. 178, no. 2, pp. 177180, 2008.

[25] A. S. Whitehouse, H. J. Smith, J. L. Drake, and M. J. Tisdale, "Mechanism of attenuation of skeletal muscle protein catabolism in cancer cachexia by eicosapentaenoic acid," Cancer Research, vol. 61, no. 9, pp. 3604-3609, 2001.

[26] E. G. Bligh and W. J. Dyer, "A rapid method of total lipid extraction and purification," Canadian Journal of Biochemistry and Physiology, vol. 37, no. 8, pp. 911-917, 1959.

[27] S. J. Iverson, S. L. C. Lang, and M. H. Cooper, "Comparison of the bligh and dyer and folch methods for total lipid determination in a broad range of marine tissue," Lipids, vol. 36, no. 11, pp. 1283-1287, 2001.

[28] N. Shirai, H. Suzuki, and S. Wada, "Direct methylation from mouse plasma and from liver and brain homogenates," Analytical Biochemistry, vol. 343, no. 1, pp. 48-53, 2005.

[29] R. W. Ogilvie and D. L. Feeback, "A metachromatic dye-ATPase method for the simultaneous identification of skeletal muscle fiber types I, IIA, IIB ands IIC," Stain Technology, vol. 65, no. 5, pp. 231-241, 1990.

[30] M. M. Bradford, "A rapid and sensitive method for the quantitation of microgram quantities of protein utilizing the principle of protein dye binding," Analytical Biochemistry, vol. 72, no. 1-2, pp. 248-254, 1976.

[31] S. Dasarathy, M. Dodig, S. M. Muc, S. C. Kalhan, and A. J. McCullough, "Skeletal muscle atrophy is associated with an increased expression of myostatin and impaired satellite cell function in the portacaval anastamosis rat," The American Journal of Physiology: Gastrointestinal and Liver Physiology, vol. 287, no. 6, pp. G1124-G1130, 2004.

[32] D. Chen, S. Chen, W. Wang, F. Liu, C. Zhang, and H. Zheng, "Modulation of satellite cells in rat facial muscle following denervation and delayed reinnervation," Acta Oto-Laryngologica, vol. 130, no. 12, pp. 1411-1420, 2010.

[33] T. Murakami, K. Hasegawa, and M. Yoshinaga, "Rapid induction of REDD1 expression by endurance exercise in rat skeletal muscle," Biochemical and Biophysical Research Communications, vol. 405, no. 4, pp. 615-619, 2011.
[34] M. Pires-Oliveira, A. L. G. C. Maragno, L. T. Parreiras-e-Silva, T. Chiavegatti, M. D. Gomes, and R. O. Godinho, “Testosterone represses ubiquitin ligases atrogin-1 and Murf-1 expression in an androgen-sensitive rat skeletal muscle in vivo," Journal of Applied Physiology, vol. 108, no. 2, pp. 266-273, 2010.

[35] L. Janjoppi, M. H. Katayama, F. A. Scorza et al., "Expression of vitamin D receptor mRNA in the hippocampal formation of rats submitted to a model of temporal lobe epilepsy induced by pilocarpine," Brain Research Bulletin, vol. 76, no. 5, pp. 480-484, 2008.

[36] H. J. Smith, P. Mukerji, and M. J. Tisdale, "Attenuation of proteasome-induced proteolysis in skeletal muscle by $\beta$ hydroxy- $\beta$-methylbutyrate in cancer-induced muscle loss," Cancer Research, vol. 65, no. 1, pp. 277-283, 2005.

[37] J. Khal and M. J. Tisdale, "Downregulation of muscle protein degradation in sepsis by eicosapentaenoic acid (EPA)," Biochemical and Biophysical Research Communications, vol. 375, no. 2, pp. 238-240, 2008.

[38] A. S. Whitehouse and M. J. Tisdale, "Downregulation of ubiquitin-dependent proteolysis by eicosapentaenoic acid in acute starvation," Biochemical and Biophysical Research Communications, vol. 285, no. 3, pp. 598-602, 2001.

[39] F. J. Soriguer, F. J. Tinahones, A. Monzón et al., "Varying incorporation of fatty acids into phospholipids from muscle, adipose and pancreatic exocrine tissues and thymocytes in adult rats fed with diets rich in different fatty acids," European Journal of Epidemiology, vol. 16, no. 6, pp. 585-594, 2000.

[40] C. Le Foll, C. Corporeau, V. Le Guen, J.-P. Gouygou, J.-P. Bergé, and J. Delarue, "Long-chain n-3 polyunsaturated fatty acids dissociate phosphorylation of Akt from phosphatidylinositol 3/-kinase activity in rats," The American Journal of Physiology: Endocrinology and Metabolism, vol. 292, no. 4, pp. E1223-E1230, 2007.

[41] S. K. Abbott, P. L. Else, and A. J. Hulbert, "Membrane fatty acid composition of rat skeletal muscle is most responsive to the balance of dietary n-3 and n-6 PUFA," British Journal of Nutrition, vol. 103, no. 4, pp. 522-529, 2010.

[42] J. M. Bando, M. Fournier, X. Da, and M. I. Lewis, "Effects of malnutrition with or without eicosapentaenoic acid on proteolytic pathways in diaphragm," Respiratory Physiology and Neurobiology, vol. 180, no. 1, pp. 14-24, 2012.

[43] D. J. Prezant, M. L. Karwa, B. Richner, D. Maggiore, E. I. Gentry, and J. Cahill, "Gender-specific effects of dexamethasone treatment on rat diaphragm structure and function," Journal of Applied Physiology, vol. 82, no. 1, pp. 125-133, 1997.

[44] M. Sandri, J. Lin, C. Handschin et al., "PGC- $1 \alpha$ protects skeletal muscle from atrophy by suppressing FoxO3 action and atrophy-specific gene transcription," Proceedings of the National Academy of Sciences of the United States of America, vol. 103, no. 44, pp. 16260-16265, 2006.

[45] R. M. Palmer and K. W. J. Wahle, "Protein synthesis and degradation in isolated muscle. Effect of $\omega 3$ and $\omega 6$ fatty acids," Biochemical Journal, vol. 242, no. 2, pp. 615-618, 1987.

[46] P. S. Sohal, V. E. Baracos, and M. T. Clandinin, "Dietary $\omega 3$ fatty acid alters prostaglandin synthesis, glucose transport and protein turnover in skeletal muscle of healthy and diabetic rats," Biochemical Journal, vol. 286, no. 2, pp. 405-411, 1992.

[47] M. L. Garg, E. Sebokova, A. B. R. Thomson, and M. T. Clandinin, " $\Delta 6$-Desaturase activity in liver microsomes of rats fed diets enriched with cholesterol and/or $\omega 3$ fatty acids," Biochemical Journal, vol. 249, no. 2, pp. 351-356, 1988. 
[48] M. J. Jackson, J. Roberts, and R. H. T. Edwards, "Effects of dietary-fish-oil feeding on muscle growth and damage in the rat," British Journal of Nutrition, vol. 60, no. 2, pp. 217-224, 1988.

[49] B. A. Clarke, D. Drujan, M. S. Willis et al., “The E3 ligase MuRF1 degrades myosin heavy chain protein in dexamethasonetreated skeletal muscle," Cell Metabolism, vol. 6, no. 5, pp. 376385, 2007.

[50] A. Jones, D.-J. Hwang, R. Narayanan, D. D. Miller, and J. T. Dalton, "Effects of a novel selective androgen receptor modulator on dexamethasone-induced and hypogonadism-induced muscle atrophy," Endocrinology, vol. 151, no. 8, pp. 3706-3719, 2010.

[51] A. P. Simopoulos, "Omega-3 fatty acids in health and disease and in growth and development," The American Journal of Clinical Nutrition, vol. 54, no. 3, pp. 438-463, 1991.

[52] D. J. Glass, "Molecular mechanisms modulating muscle mass," Trends in Molecular Medicine, vol. 9, no. 8, pp. 344-350, 2003.

[53] R. A. Frost, D. Huber, A. Pruznak, and C. H. Lang, "Regulation of REDD1 by insulin-like growth factor-I in skeletal muscle and myotubes," Journal of Cellular Biochemistry, vol. 108, no. 5, pp. 1192-1202, 2009.

[54] R. M. R. Pereira and J. Freire de Carvalho, "Glucocorticoidinduced myopathy," Joint Bone Spine, vol. 78, no. 1, pp. 41-44, 2011.

[55] M. F. W. te Pas, P. R. de Jong, and F. J. Verburg, "Glucocorticoid inhibition of $\mathrm{C} 2 \mathrm{C} 12$ proliferation rate and differentiation capacity in relation to mRNA levels of the MRF gene family," Molecular Biology Reports, vol. 27, no. 2, pp. 87-98, 2000.

[56] O. Prelovsek, T. Mars, M. Jevsek, M. Podbregar, and Z. Grubic, "High dexamethasone concentration prevents stimulatory effects of TNF- $\alpha$ and LPS on IL- 6 secretion from the precursors of human muscle regeneration," The American Journal of Physiology: Regulatory Integrative and Comparative Physiology, vol. 291, no. 6, pp. R1651-R1656, 2006.

[57] E. Castillero, A. I. Martín, M. López-Menduiña, M. A. Villanúa, and A. López-Calderón, "Eicosapentaenoic acid attenuates arthritis-induced muscle wasting acting on atrogin-1 and on myogenic regulatory factors," The American Journal of Physiology: Regulatory Integrative and Comparative Physiology, vol. 297, no. 5, pp. R1322-R1331, 2009. 

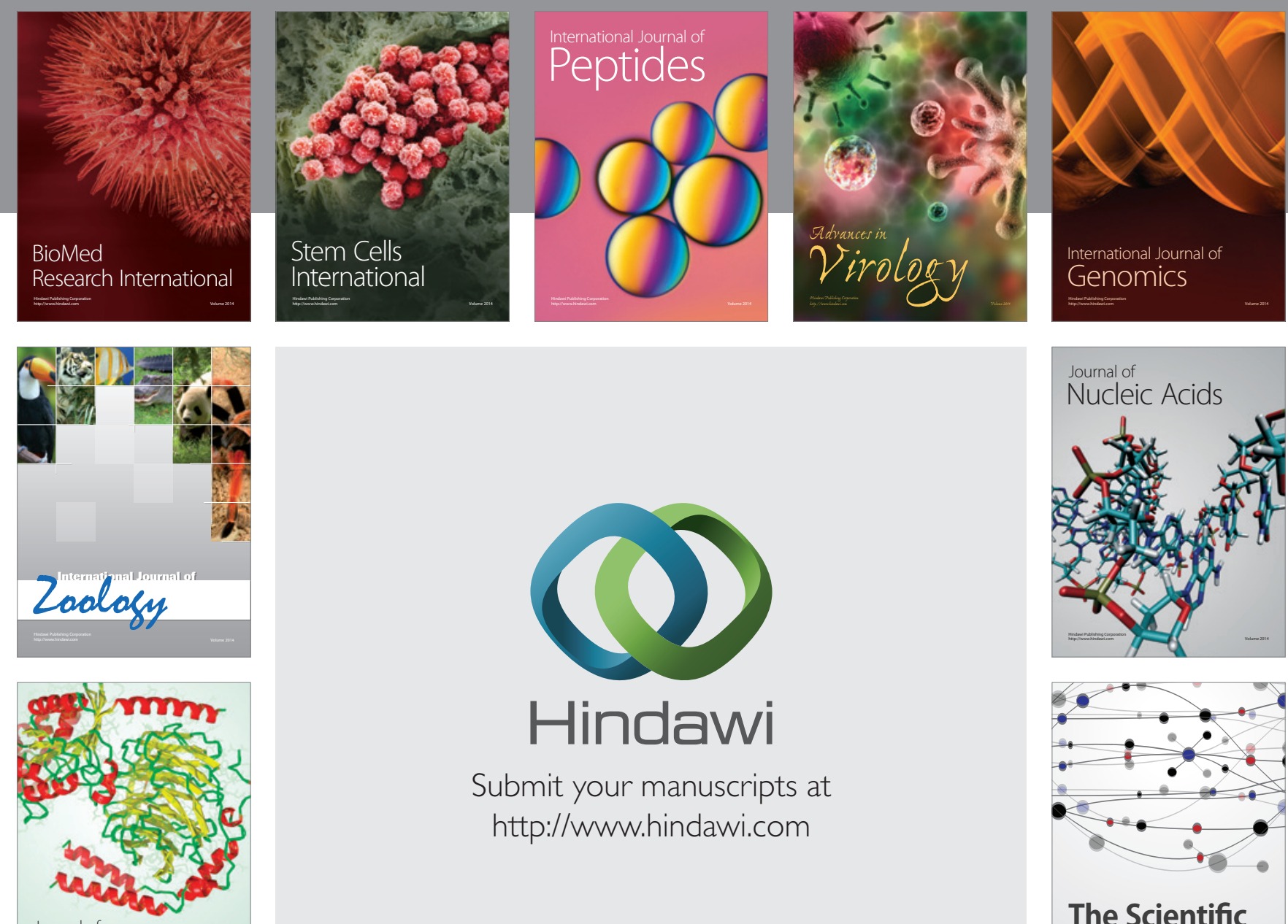

Submit your manuscripts at

http://www.hindawi.com

Journal of
Signal Transduction
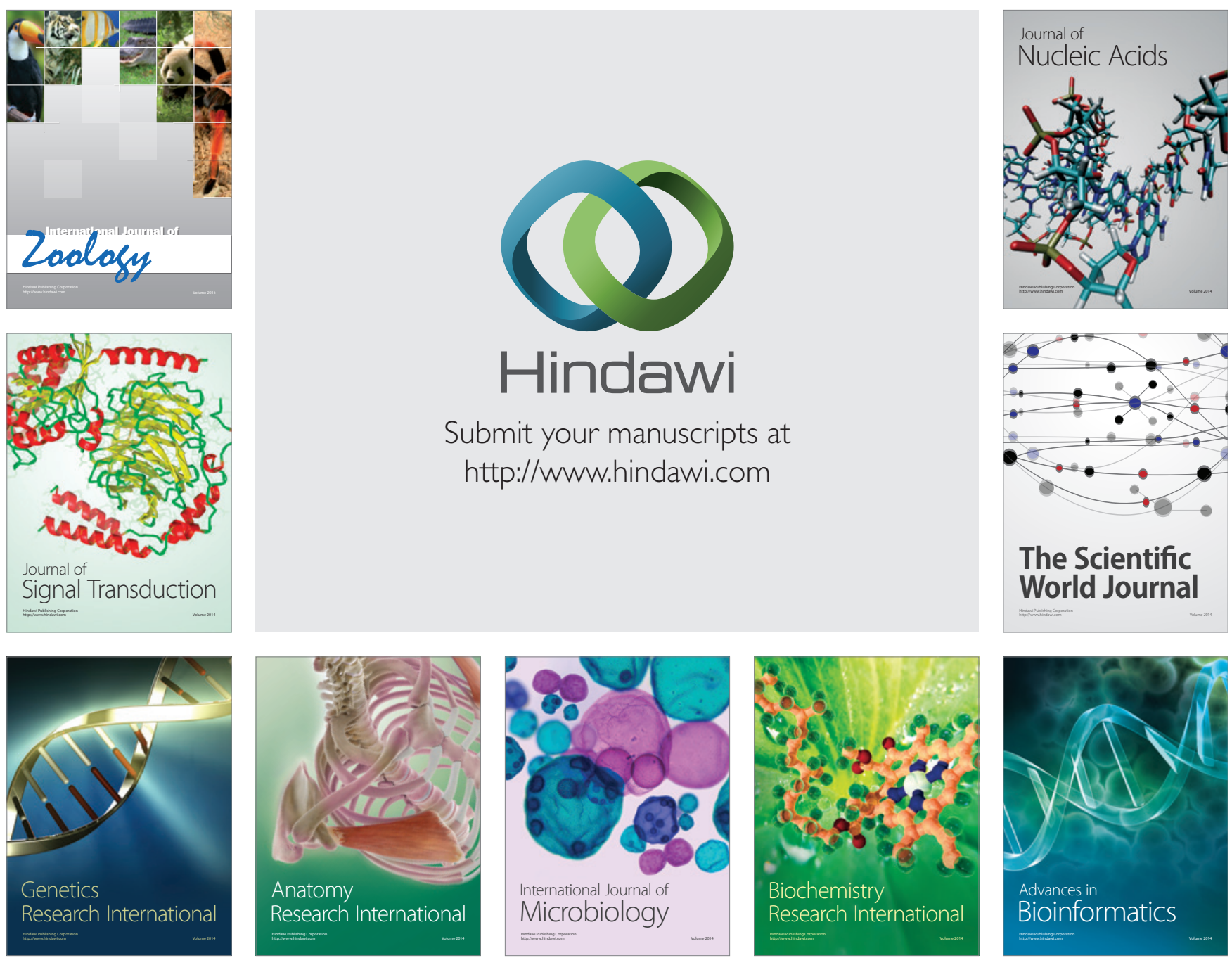

The Scientific World Journal
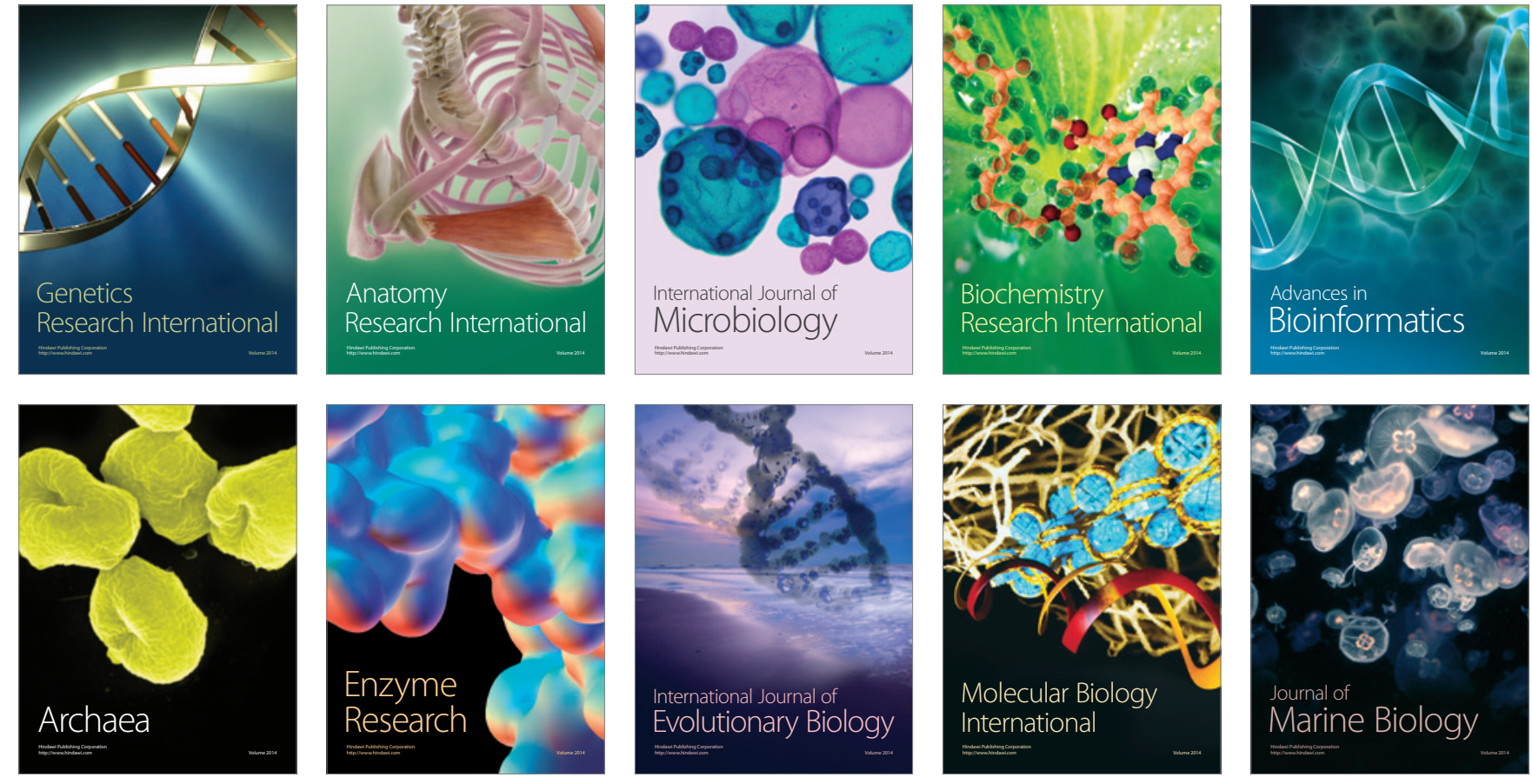